\title{
O TRABALHO DO DIRIGENTE DA PEQUENA EMPRESA PODE SER DESCRITO PELOS PAPÉIS DO ADMINISTRADOR? ${ }^{1}$
}

\section{THE WORK MANAGER'S OF THE SMALL BUSINESS CAN BE DESCRIBED BY ADMINISTRATOR'S ROLES?}

\author{
Jair de Oliveira ${ }^{2}$ \\ Edmundo Escrivão Filho ${ }^{3}$ \\ Marcelo Sido Nagano ${ }^{4}$ \\ Antonio Sergio Ferraudo 5
}

RESUMO: Este trabalho apresenta os resultados de uma pesquisa de campo realizada com pequenas empresas localizadas na região central do estado de São Paulo, cujo objetivo principal foi "verificar a conveniência de o trabalho do dirigente da pequena empresa ser descrito pelos papéis do administrador". A pesquisa coletou dados de 47 empresas por meio de questionário semi-estruturado e foi classificada como aplicada, quantitativa e descritiva. Para análise dos dados utilizou-se as técnicas estatísticas multivariadas de análise de agrupamento e de análise de componentes principais. Os resultados consignaram o desenvolvimento de um instrumento de coleta de dados apropriado para verificar a realização do trabalho do dirigente da pequena empresa, o entendimento de que a abordagem dos papéis é útil para explicar o trabalho do dirigente e a identificação de um conjunto de papéis mais representativo do trabalho do dirigente.

PALAVRAS-CHAVE: pequena empresa, trabalho do administrador, papéis do administrador.

ABSTRACT: This paper presents the results of a field research with small firms located in central São Paulo state, whose primary objective was "verify the usefulness of the work of the leader of the small firm is described by the roles of the administrator". The survey collected data from 47 companies through semi-structured questionnaire and was classified as applied, quantitative and descriptive. It was used the multivariate techniques of cluster analysis and principal component analysis. The results consigned to develop an instrument to collect appropriate data to verify the completion of the work of the leader of small business, understanding that approach the roles is useful for explaining the work of a manager and to identify a set of papers more representative the work of the leader.

KEY WORDS: small business, work manager's, roles of the administrator.

\footnotetext{
${ }^{1}$ Artigo Recebido em 06.10.2010. Revisado por pares em 03.11.2010. Recomendado em 28.04.2011 por Leomar dos Santos Editor. Publicado em 25.07.2011.

Organização Responsável pelo periódico: Universidade regional de Blumenau - FURB - www.furb.br/rn

${ }^{2}$ Universidade Federal Tecnologia do Paraná - UFTPR - jair37@gmail.com

${ }^{3}$ Universidade São Paulo - USP - edesfi@sc.usp.br

${ }^{4}$ Universidade São Paulo - USP - drnagano@sc.usp.br

${ }^{5}$ Universidade Estadual Paulista - UNESP - fsajago@gmail.com
} 


\section{INTRODUÇÃO}

No século XX formou-se e desenvolveu-se o moderno pensamento administrativo, amplamente fundamentado nas necessidades das grandes empresas (DANDRIDGE, 1979; D'AMBOISE; MULDOWNEY, 1988). Em meados da década de 70 do século passado, houve uma reversão na participação da pequena empresa, ao menos no número de estabelecimento e no emprego total, não concretizando a previsão de seu desaparecimento (SOLOMON, 1989; JULIEN, 1997). Essa reversão não significa, no entanto, uma redução da concentração da riqueza empresarial, pois as cem maiores empresas tinham aproximadamente 40\% dos ativos das empresas em 1948 e passaram para cerca de 70\% em 1991 (HEILBRONER; THUROW, 2001, p.73). O "espírito" do período foi de empreendedorismo e da "re-emergência da pequena empresa" (LOVEMAN; SENGERBERGER, 1990).

Portanto, vozes se levantaram contra o predomínio de princípios e métodos das grandes empresas no pensamento administrativo e de sua inadequação aos problemas das pequenas empresas. Nos últimos 30 ou 40 anos, a literatura sobre a pequena empresa cresceu na busca de suas características específicas; o lema era "a pequena não é uma grande que ainda não cresceu" como uma criança não é um adulto, pois suas naturezas são muito diferentes (DANDRIDGE, 1979; CHURCHILL; LEWIS, 1983; D'AMBOISE; MULDOWNEY, 1988; JULIEN, 1997). Este propósito foi importante no esforço de mostrar que a pequena empresa era diferente da grande; no entanto, assumiu o pressuposto de que o seu setor é homogêneo.

Mais recentemente, os estudos acentuam que, em várias características, as pequenas empresas são heterogêneas; sendo, portanto, a sua diversidade uma das dificuldades em estudá-las (SOUZA; MAZZALI, 2008; TORRÈS; JULIEN, 2005). Outra característica inerente a essas empresas é a volatilidade, causada pelo grande número de criação e de encerramento de atividades nos primeiros anos de existência. Essas circunstâncias, a heterogeneidade e a volatilidade, explicam em parte o atraso dos estudos e as dificuldades em propor teorias e conclusões adequadas e diferentes daquelas aplicadas às grandes (DANDRIDGE, 1979; LEONE, 1991; 1999). Apesar dessas limitações, as pesquisas registram avanços importantes na compreensão das pequenas empresas, entre eles: mostrar a sua contribuição econômica e social; tratar os modelos de gestão, em particular os perfis dos gestores; e qualificar suas especificidades organizacionais (DANDRIDGE, 1979; D'AMBOISE; MULDOWNEY, 1988; LEONE, 1991; 1999; FILLION, 1999).

Portanto, mesmo reconhecendo a heterogeneidade como uma das dificuldades em definir as pequenas empresas, um esforço precisa ser despendido para encontrar suas especificidades, relacionar tais características e especificar em que condições o comportamento dessas características é alterado (DANDRIDGE, 1979; D'AMBOISE; MULDOWNEY, 1988; LEONE, 1991; 1999).

Infelizmente, prevalecem na pesquisa, na literatura e no ensino sobre o trabalho do administrador as proposições teóricas tendo a grande empresa como objeto de estudo. Esta corrente de pensamento administrativo realizou grandes contribuições, mostrou aspectos importantes sobre como o administrador despende seu tempo; apresentou recomendações, modelo e sugestões para interpretar o trabalho do administrador por meio de funções 


\section{O TRABALHO DO DIRIGENTE DA PEQUENA EMPRESA PODE SER DESCRITO PELOS PAPÉIS DO ADMINISTRADOR?}

administrativas, de desempenho de papéis ou de submetido a uma agenda, mas não forneceu respostas sobre a realidade da pequena empresa (CARLSON, 1951; MINTZBERG, 1973; STEWART, 1976).

As duas abordagens que receberam maior contribuição sobre o trabalho do administrador ao longo dos anos foram: a do processo, proposta por Fayol, e a dos papéis, formulada por Mintzberg. Porém, questiona-se se as descrições dessas abordagens se adequam à realidade da pequena empresa. Assim, examinando-se especificamente neste trabalho a abordagem dos papéis, propõe-se uma discussão sobre a aderência de suas explicações teóricas quando conduzida à realidade da pequena empresa. Para tanto, identificase o seguinte problema de pesquisa: A descrição teórica da abordagem dos papéis sobre o trabalho do administrador é útil para explicar o trabalho do dirigente da pequena empresa? Para pesquisar esse problema, projetou-se uma pesquisa empírica com o objetivo de verificar a conveniência de o trabalho do dirigente da pequena empresa ser descrito pelos papéis do administrador. Este artigo é uma comunicação dos resultados da pesquisa e está organizado em cinco seções. Esta seção trata da apresentação do tema, problema e objetivo da pesquisa. A próxima, sobre o marco teórico, examina uma das descrições do trabalho do administrador, a abordagem dos papéis. A terceira trata dos métodos de pesquisa, a quarta da análise dos dados e, por fim, a quinta apresenta a conclusão.

\section{MARCO TEÓRICO}

\subsection{Abordagem dos papéis do administrador}

Entre 1960 e 1970, Mintzberg realizou várias pesquisas sobre o trabalho do administrador (RAUFFLET, 2005). Mintzberg (1973; 1975) representou a atividade do administrador como sequencial e derivada da autoridade formal sobre uma determinada unidade. A sequência inicia com o desenvolvimento de relações interpessoais, as quais conduzem ao acesso de informação, que capacita os administradores a tomarem decisões e, então, a formular as estratégias necessárias. Esses três grupos representam pelo menos dez tipos de papéis desempenhados pelo administrador em seu cotidiano. Eles mudam de grau de importância conforme a posição hierárquica do administrador na organização e são contingenciados por fatores ambientais, por características pessoais do administrador e por variações decorrentes de fatores temporais, cíclicos ou eventuais (MINTZBERG, 1973).

Os dez papéis não se desassociam facilmente; pelo contrário, eles formam um todo integrado e a ausência de um papel pode prejudicar a ação do administrador. A atribuição do grau de importância a um determinado papel depende do cargo que o administrador ocupa na organização (MINTZBERG, 1973); por exemplo, um administrador de produção se dedicará mais aos papéis decisionais, pois eles retratam uma maior preocupação com o fluxo de trabalho e a orientação das tarefas (MINTZBERG, 1975); enquanto que o administrador do setor de vendas priorizará mais os papéis interpessoais e a orientação às pessoas (MINTZBERG, 1975).

A seguir, será apresentada uma descrição dos dez papéis desempenhados pelo administrador, divididos em três grupos. O primeiro grupo interpessoal congrega três funções básicas do administrador (MINTZBERG, 1973; 1975): 
- de representante: quando representa a organização por meio da sua autoridade formal e status, em atividades cerimoniais e protocolares. Esse papel é mais significativo nos níveis mais elevados da organização. Por exemplo, a participação em cerimônias de concessão de prêmios ou de títulos acadêmicos e o recebimento ou a visita a clientes e fornecedores. $\mathrm{O}$ administrador exerce esse papel participando de encontros, cujos objetivos não sejam relacionados diretamente a contatos com subordinados e para efetuar negociações.

- de líder: porque é responsável pelo relacionamento com os subordinados. Ele providencia a seleção, a contratação e o treinamento dos funcionários. Ele comunica ordens e orientações aos subordinados sobre como determinadas atividades devem ser realizadas. Ele critica, reconhece e motiva os subordinados, além de exercitar sua liderança durante a execução dos demais papéis. A incumbência do líder é integrar os interesses individuais com as metas organizacionais. Assim, constantemente ele acompanha a execução das operações e verifica quais estão erradas e quais problemas precisam de sua atenção.

- de contato: quando desenvolve e mantém relacionamentos com outros administradores, superiores, clientes, fornecedores ou consultores. Nesse papel, ele desenvolve atividades para manter um conjunto de relações formais e informais dentro e fora da organização; e para obter as informações necessárias para administrar a empresa.

O segundo grupo, informacionais, inclui os seguintes papéis (MINTZBERG, 1973; 1975):

- de monitor: quando monitora o que acontece em sua unidade de trabalho. Para monitorar, o administrador primeiro busca informações sobre as operações internas da sua unidade e sobre os eventos externos; analisa os eventos e avalia ideias e tendências. Segundo Konrad et al (2001), durante o monitoramento, o administrador conversa com diferentes pessoas sobre os planos da empresa e as decisões de outros administradores. Ele monitora o que os competidores fazem e os acontecimentos do ambiente externo que possam impactar nos resultados de seu departamento.

- de disseminador: porque é o responsável pela transmissão das informações essenciais dentro do seu espaço de trabalho. Segundo Konrad et al (2001), o administrador comunica por meio verbal ou por escrito, em reunião ou em conversa pessoal, as informações relevantes para sua unidade de trabalho.

- de porta-voz: quando providencia o envio de informações sobre a sua organização à comunidade externa. Ele concede entrevistas, realiza discursos, participa de reuniões de associações de classes e eventos que exijam um pronunciamento sobre a história ou a situação da organização.

O terceiro grupo, papéis decisionais, inclui quatro funções básicas do administrador:

- de empreendedor: quando ele se dedica a melhorar a sua unidade e a promover voluntariamente mudanças. O administrador planeja e desenvolve melhorias nos fluxos de trabalho, individualmente ou coordenando equipes; identifica novas oportunidades de negócios ou melhorias para o negócio atual (KONRAD et al, 2001); em muitas situações, ele coordena e supervisiona a implantação dos projetos de melhorias.

- de solucionador de distúrbios: quando ele responde involuntariamente às pressões e às mudanças que ocorrem em sua unidade de trabalho, age corretivamente para solucionar os 


\section{O TRABALHO DO DIRIGENTE DA PEQUENA EMPRESA PODE SER DESCRITO PELOS PAPÉIS DO ADMINISTRADOR?}

problemas advindos de situações imprevistas e resolve os impasses e os conflitos que ocorrem entre os subordinados.

- de alocador de recursos: porque ele precisa decidir sobre a aplicação de todos os recursos financeiros, tempo, material, equipamentos e trabalho de sua unidade. Ele pratica as atividades de alocador de recursos quando agenda os seus compromissos e de seus subordinados, elabora e aprova orçamentos, analisa e seleciona projetos que demandam investimentos, programa os trabalhos a serem realizados, autoriza a tomada de decisão sobre alocação de recursos e analisa os projetos de outras pessoas.

- de negociador: porque é o responsável por conduzir as negociações com indivíduos ou representantes de outras organizações. $\mathrm{O}$ administrador persuade outros administradores ou interessados a cooperarem com os projetos que ele conduz. Ele negocia acordos trabalhistas e governamentais, a troca de informação, de produtos, de serviços e a participação pessoal ou dos subordinados em eventos.

\subsection{Hipótese sobre os papéis do administrador}

Procurando averiguar como os papéis do administrador se relacionam com o trabalho realizado pelo dirigente da pequena empresa, formulou-se a seguinte hipótese:

- H0: Não existe relação entre os papéis do administrador com o trabalho realizado pelo dirigente da pequena empresa.

- H1: Existe uma relação entre os papéis do administrador e o trabalho realizado pelo dirigente da pequena empresa.

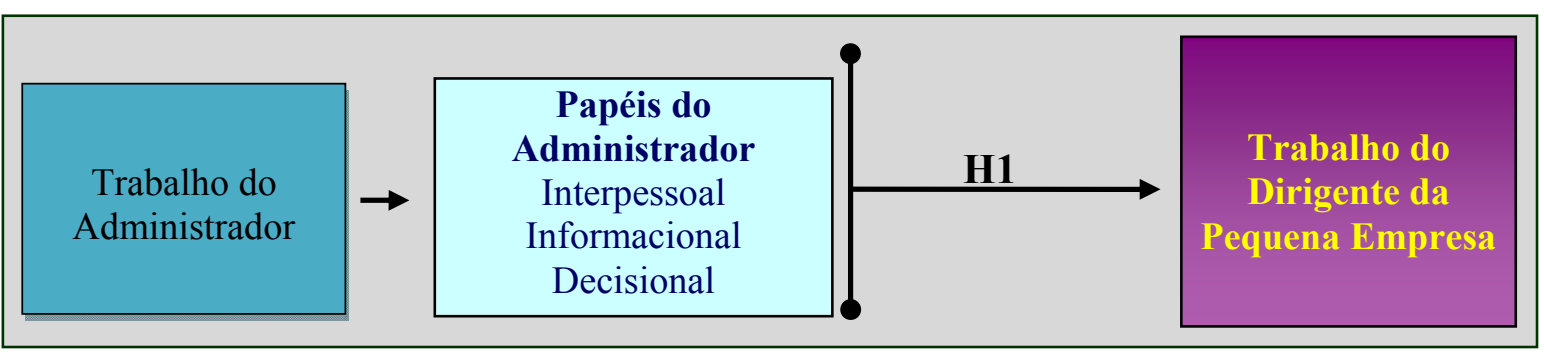

Figura 1 - Hipótese da pesquisa

\section{MÉTODOS DE PESQUISA}

Esta seção apresenta as características do trabalho de campo realizado.

\subsection{Caracterização da pesquisa}

Esta pesquisa é considerada como aplicada, quanto à sua natureza, porque contribui para fins práticos, relacionando o trabalho do dirigente da pequena empresa de vários setores econômicos com os papéis do administrador. Quanto à abordagem do problema, é considerada como quantitativa porque usa quantificação, tanto na coleta como no tratamento dos dados e aplica técnicas estatísticas para analisar as variáveis. Quanto ao tipo de pesquisa é considerada como descritiva porque relaciona os papéis do administrador na pequena empresa do setor metal-mecânico com outras variáveis organizacionais. Quanto aos procedimentos técnicos é considerada como levantamento (survey), porque se procede à interrogação dos 
dirigentes das pequenas empresas, para, posteriormente, mediante análise estatística, obter conclusões correspondentes ao trabalho que eles desenvolvem na condução da empresa (GIL, 1999).

\subsection{Escolha das empresas participantes do estudo}

Segundo Fink (1995), nas pesquisas conduzidas por survey, a amostra deve representar um conjunto pré-definido de características da população e incluir os requisitos para responder os objetivos da pesquisa. Como característica da amostra busca-se dirigentes que atuam diretamente na administração de pequenas empresas. Foram adotados na pesquisa os critérios do SEBRAE (2006) e do Small Business Administration (SBA, 2008) para definir pequena empresa. Esses critérios classificam o tamanho das empresas de acordo com o número de funcionários, considerando o setor econômico de atuação e a independência com relação às grandes empresas. Portanto, será considerada pequena empresa aquela do setor da indústria com até 500 empregados; e dos setores do comércio, serviço e agropecuária com até 99 funcionários.

A amostra é considerada por conveniência e composta por pequenas empresas dos setores indústria, comércio, serviços e agropecuário, instaladas na região de São Carlos, município do estado de São Paulo. A amostra foi obtida em dois momentos. O primeiro, de pequenas empresas participantes de um evento promovido pelo Escritório do SEBRAESP/Araraquara sobre inovação tecnológica na pequena empresa, no dia 26 de agosto de 2009. Ao final do evento, os empresários presentes foram convidados a participarem da pesquisa, respondendo voluntariamente ao questionário. O segundo grupo foi composto de dezoito pequenas empresas entrevistadas durante a segunda e a terceira semanas de setembro de 2009 .

\subsection{Questionário}

Para examinar a hipótese proposta neste trabalho, elaborou-se um questionário com duas seções. Na primeira foram incluídas questões para caracterizar o entrevistado e a empresa. Elas auxiliam na estratificação de perfil dos entrevistados e no enquadramento das empresas nos respectivos portes.

\begin{tabular}{|c|c|c|}
\hline \multicolumn{3}{|c|}{ PAPÉIS DO ADMINISTRADOR } \\
\hline Papel & Construto & Descrição \\
\hline \multirow{3}{*}{ Representante } & $\begin{array}{l}\text { Participação em eventos } \\
\text { sociais }\end{array}$ & $\begin{array}{l}\text { Participa de eventos externos, como cerimônias de concessão } \\
\text { de prêmios ou de entidade de classe. }\end{array}$ \\
\hline & Atendimento aos visitantes & $\begin{array}{l}\text { Atende a pessoas que procuram a empresa, mas não são } \\
\text { clientes. }\end{array}$ \\
\hline & Promoção de eventos sociais & $\begin{array}{l}\text { Realiza eventos sociais para promover a imagem ou produtos } \\
\text { da empresa. }\end{array}$ \\
\hline \multirow{3}{*}{ Líder } & $\begin{array}{l}\text { Orientação da execução das } \\
\text { tarefas }\end{array}$ & $\begin{array}{l}\text { Define metas de trabalho e comunica ordens e orientações aos } \\
\text { subordinados. }\end{array}$ \\
\hline & $\begin{array}{l}\text { Relacionamento com os } \\
\text { subordinados }\end{array}$ & Critica, reconhece e motiva os subordinados. \\
\hline & Exercício da autoridade & $\begin{array}{l}\text { Percebe que os subordinados compreendem perfeitamente as } \\
\text { orientações, as aceitam e as cumprem. }\end{array}$ \\
\hline \multirow{3}{*}{ Contato } & Relacionamento interno & $\begin{array}{l}\text { Desenvolve atividades para manter um conjunto de relações } \\
\text { formais e informais dentro da empresa. }\end{array}$ \\
\hline & Relacionamento externo & Estabelece relacionamentos profissionais externos. \\
\hline & Disseminação de & Repassa informações externas importantes aos funcionários. \\
\hline
\end{tabular}




\section{O TRABALHO DO DIRIGENTE DA PEQUENA EMPRESA PODE SER DESCRITO PELOS PAPÉIS DO ADMINISTRADOR?}

\begin{tabular}{|c|l|l|}
\hline & informações internas & \\
\hline \multirow{5}{*}{ Monitor } & Obtenção de informações & Identifica e coleta informações relevantes para a empresa. \\
\cline { 2 - 3 } & $\begin{array}{l}\text { Monitoramento das } \\
\text { operações internas }\end{array}$ & $\begin{array}{l}\text { Avalia o desempenho da empresa, a fim de realizar ajustes e } \\
\text { mudanças. }\end{array}$ \\
\cline { 2 - 3 } & $\begin{array}{l}\text { Acompanhamento dos } \\
\text { eventos externos }\end{array}$ & $\begin{array}{l}\text { Verifica o que os competidores fazem e os acontecimentos do } \\
\text { ambiente externo. }\end{array}$ \\
\hline
\end{tabular}

Quadro 2 (Continuação) - Construtos teóricos para os papéis do administrador Segunda Seção

\begin{tabular}{|c|c|c|}
\hline \multirow{3}{*}{ Disseminador } & Seleção de informações & $\begin{array}{l}\text { Classifica quais informações relevantes serão compartilhadas } \\
\text { com os subordinados. }\end{array}$ \\
\hline & Compartilha informações & Compartilha informações relevantes com os subordinados. \\
\hline & $\begin{array}{l}\text { Assegura o recebimento de } \\
\text { informações }\end{array}$ & $\begin{array}{l}\text { Assegura que os subordinados recebam informações relevantes } \\
\text { para a execução da tarefa. }\end{array}$ \\
\hline \multirow{3}{*}{ Porta-voz } & Realização de comunicados & $\begin{array}{l}\text { Concede entrevista ou realiza discursos ou apresenta } \\
\text { informações da empresa para públicos externos. }\end{array}$ \\
\hline & $\begin{array}{l}\text { Comunicação em nome da } \\
\text { empresa }\end{array}$ & $\begin{array}{l}\text { Pronuncia-se sobre a história ou a situação da empresa em } \\
\text { eventos ou reuniões. }\end{array}$ \\
\hline & Representação do setor & Reivindica benefícios para as empresas do setor. \\
\hline \multirow{3}{*}{ Empreendedor } & Promoção de melhorias & $\begin{array}{l}\text { Altera os fluxos de trabalho, a fim de melhorar a } \\
\text { produtividade. }\end{array}$ \\
\hline & Proposição de oportunidades & $\begin{array}{l}\text { Procura por inovações que possam se tornar projetos da } \\
\text { empresa. }\end{array}$ \\
\hline & $\begin{array}{l}\text { Implementação de novos } \\
\text { projetos }\end{array}$ & $\begin{array}{l}\text { Conduz a implantação de projetos de melhoria ou mudança de } \\
\text { produto, serviço e métodos de produção ou de gestão. }\end{array}$ \\
\hline \multirow{3}{*}{$\begin{array}{l}\text { Manipulador } \\
\text { de distúrbios }\end{array}$} & $\begin{array}{l}\text { Resolução de conflitos } \\
\text { rotineiros }\end{array}$ & $\begin{array}{l}\text { Resolve os conflitos entre os subordinados, advindos de } \\
\text { situações rotineiras. }\end{array}$ \\
\hline & $\begin{array}{l}\text { Resolução de conflitos } \\
\text { repentinos }\end{array}$ & $\begin{array}{l}\text { Resolve os conflitos entre os subordinados, advindos de } \\
\text { situações inesperadas. }\end{array}$ \\
\hline & Resolução de impasses & Resolve os impasses entre subordinados e outras pessoas. \\
\hline \multirow{3}{*}{$\begin{array}{l}\text { Alocador de } \\
\text { recursos }\end{array}$} & $\begin{array}{l}\text { Programação de } \\
\text { compromissos }\end{array}$ & Agenda compromissos pessoais e dos subordinados. \\
\hline & Avaliação de orçamentos & $\begin{array}{l}\text { Decide sobre investimentos da empresa (analisa e seleciona } \\
\text { projetos que demandem aplicação de recursos financeiros). }\end{array}$ \\
\hline & Alocação de recursos & $\begin{array}{l}\text { Aloca os recursos financeiros, materiais e físicos, a fim de } \\
\text { maximizar sua eficiência. }\end{array}$ \\
\hline \multirow{3}{*}{ Negociador } & Negociação de cooperação & $\begin{array}{l}\text { Persuade outras pessoas a cooperarem com projetos da } \\
\text { empresa. }\end{array}$ \\
\hline & Negociação de acordos & $\begin{array}{l}\text { Negocia acordos com entidades de classe, governamentais e } \\
\text { jurídicas. }\end{array}$ \\
\hline & Negociação de transações & $\begin{array}{l}\text { Negocia a comercialização de produtos e serviços ou acordos } \\
\text { com outras empresas. }\end{array}$ \\
\hline
\end{tabular}

Quadro 1 - Construtos teóricos para os papéis do administrador - Segunda Seção

Fonte: Elaborado pelo autor.

Na segunda seção do questionário, constam as questões sobre os três grupos de papéis do administrador divididos em dez papéis $(1973$; 1975), conforme apresentado nos quadros 1 e 2. Foram estabelecidos três construtos para cada papel.

$\mathrm{Na}$ elaboração do questionário, além dos construtos apresentados nos quadros 1 e 2 , utilizou-se os trabalhos de Anderson, Murray e Olivarez Jr. (2002) e de Pearson e Chatterjee (2003). Assim, foram elaborados para esta seção do questionário dez construtos, com três questões cada um. As questões foram formuladas seguindo uma escala tipo Likert, com sete 
pontos: o número 1 significava muito raramente; o número 7 , muito frequentemente; e o número 4 , o ponto neutro.

\section{ANÁLISE DOS DADOS E RESULTADOS}

Os dados foram analisados usando-se o pacote estatístico Statistica, versão 8. Optou-se pelas análises de agrupamento por métodos hierárquico e não-hierárquico, cujo objetivo é identificar estruturas de grupos contidas nos dados originais e interpretá-las segundo seus padrões. Em complemento, os dados foram submetidos à análise de componentes principais que busca discriminar aquelas amostras ou objetos com padrões diferenciados (HAIR et al, 2006).

\subsection{Caracterização da amostra}

Participaram do estudo 47 empresas, a maioria (70\%) com faturamento anual em 2008 até 240 mil reais; $27 \%$ com faturamento acima de 240 mil até 2,4 milhões de reais; e 3\% com faturamento acima de 2,4 milhões. O setor serviços foi o mais representativo, com $61,7 \%$ das empresas, seguido da indústria com $23 \%$, do comércio com 10,6\% e agropecuário com 4,7\%. O sexo preponderante dos entrevistados foi o masculino com $64 \%$ dos respondentes. Quanto à formação dos empresários, $12,7 \%$ possuíam pós-graduação; $48,9 \%$ possuíam graduação e $38,4 \%$ pelo menos o ensino médio. Além disso, conforme tabela 1 , a média de idade dos respondentes foi de 41 anos; o tempo de vida das empresas, de 12 anos; e o número médio de funcionários em 2008 e 2009 foi de 12 e 13, respectivamente.

Tabela 1 - Descrição da amostra

\begin{tabular}{lrrrr}
\hline & Média & Mínimo & Máximo & \multicolumn{1}{c}{ DP } \\
\hline Idade dos respondentes & 41 & 29 & 55 & 7,0 \\
Tempo de vida da empresa & 12 & 1 & 39 & 10,8 \\
Funcionários - 2008 & 12 & 0 & 220 & 32,2 \\
Funcionários - 2009 & 13 & 0 & 220 & 32,3 \\
\hline
\end{tabular}

Fonte: Pesquisa de campo

\subsection{Análise de confiabilidade das escalas do questionário}

Para a análise da confiabilidade das escalas, verificou-se a opção coerência interna. Utilizou-se nessa análise o alfa de Cronbach. Os coeficientes para análise dos resultados estão expostos na tabela 2. Arbitrou-se, como valores de alfa de Cronbach aceitável para a escala, valor acima de 0,6 .

Tabela 2 - Definição dos coeficientes de Correlação e de Cronbach para o pré-teste

\begin{tabular}{|c|c|c|c|c|c|}
\hline & $\begin{array}{l}\text { Muito } \\
\text { Baixa }\end{array}$ & $\begin{array}{l}\text { Baixa ou } \\
\text { Fraca }\end{array}$ & Moderada & Alta ou Forte & $\begin{array}{l}\text { Muito Alta ou } \\
\text { Muito Forte }\end{array}$ \\
\hline \multicolumn{6}{|l|}{ Cronbach - $\alpha$} \\
\hline Confiabilidade & $\alpha \leq 0,30$ & $0,30<\alpha \leq 0,60$ & $0,60<\alpha \leq 0,75$ & $0,75<\alpha \leq 0,90$ & $\alpha>0,90$ \\
\hline
\end{tabular}




\section{O TRABALHO DO DIRIGENTE DA PEQUENA EMPRESA PODE SER DESCRITO PELOS PAPÉIS DO ADMINISTRADOR?}

A tabela 3, modelo baseado na sugestão de Gliem e Gliem (2003), apresenta os resultados dos testes de confiabilidade interna. $\mathrm{O}$ alfa de Cronbach total alcançado foi de 0,91 , considerado adequado para a aplicação dos testes estatísticos. Os valores de alfa, se alguma pergunta fosse retirada, reforçariam o poder do alfa como muito forte, pois a retirada de algum dos itens não melhoraria os resultados, conforme apresentado na tabela 3.

Tabela 3 - Análise do Alfa de Cronbach

\begin{tabular}{|c|c|c|c|c|c|}
\hline \multirow{2}{*}{$\begin{array}{l}\text { Estatística } \\
\text { da escala }\end{array}$} & $\mathrm{N}-$ Escala & $\mathrm{N}-$ Casos & Média & Variância & Desvio Padrão \\
\hline & 30 & 47 & 136,3 & 945,7 & 30,75 \\
\hline $\begin{array}{c}\text { (alguns resultados) } \\
\text { Pergunta }\end{array}$ & $\begin{array}{l}\text { Escala média, se } \\
\text { item desprezado }\end{array}$ & $\begin{array}{c}\text { Variância da } \\
\text { escala, se item } \\
\text { desprezado }\end{array}$ & \multicolumn{2}{|c|}{$\begin{array}{l}\text { DP da escala, se } \\
\text { item desprezado }\end{array}$} & $\begin{array}{c}\text { Alfa, } \\
\text { se pergunta } \\
\text { deletada }\end{array}$ \\
\hline REP1 & 132,8298 & & & 29,77599 & 0,909809 \\
\hline REP2 & 131,5532 & & & 30,13926 & 0,913432 \\
\hline REP3 & 133,1277 & & & 29,90170 & 0,910158 \\
\hline EMP1 & 131,2766 & & & 28,48792 & 0,920237 \\
\hline EMP2 & 131,2553 & & & 29,25200 & 0,904938 \\
\hline EMP3 & 131,5957 & & & 29,16545 & 0,904126 \\
\hline SOL1 & 131,9362 & & & 29,77247 & 0,909580 \\
\hline SOL2 & 131,8936 & & & 29,89146 & 0,910289 \\
\hline SOL3 & 131,9362 & & & 29,47152 & 0,907397 \\
\hline \multirow{2}{*}{\multicolumn{3}{|c|}{ Coeficiente de confiabilidade dos 30 itens }} & \multicolumn{2}{|c|}{ Alfa } & fa Padronizado \\
\hline & & & \multicolumn{2}{|c|}{$\mathbf{0 , 9 1}$} & 0,919 \\
\hline
\end{tabular}

Fonte: tratamento dos dados.

Finalizando esta seção, observaram-se ainda os valores alfa de Cronbach para os dez construtos da escala. $\mathrm{O}$ construto Representante apresenta valor menor que 0,6 , para o alfa e o alfa padronizado, 0,44 e 0,45 respectivamente. No entanto, a retirada de alguma pergunta desse construto não melhoraria o valor do alfa; por isso, optou-se por manter esse construto nas discussões, a fim de se analisar mais detalhadamente essa situação.

\subsection{Análise dos dados}

Utilizando-se as médias e os desvios-padrão das variáveis da amostra, observou-se que os papéis de Representante, de Porta-voz e de Negociador apresentam pelo menos um item com valores médios abaixo de quatro, conforme gráfico 1. 


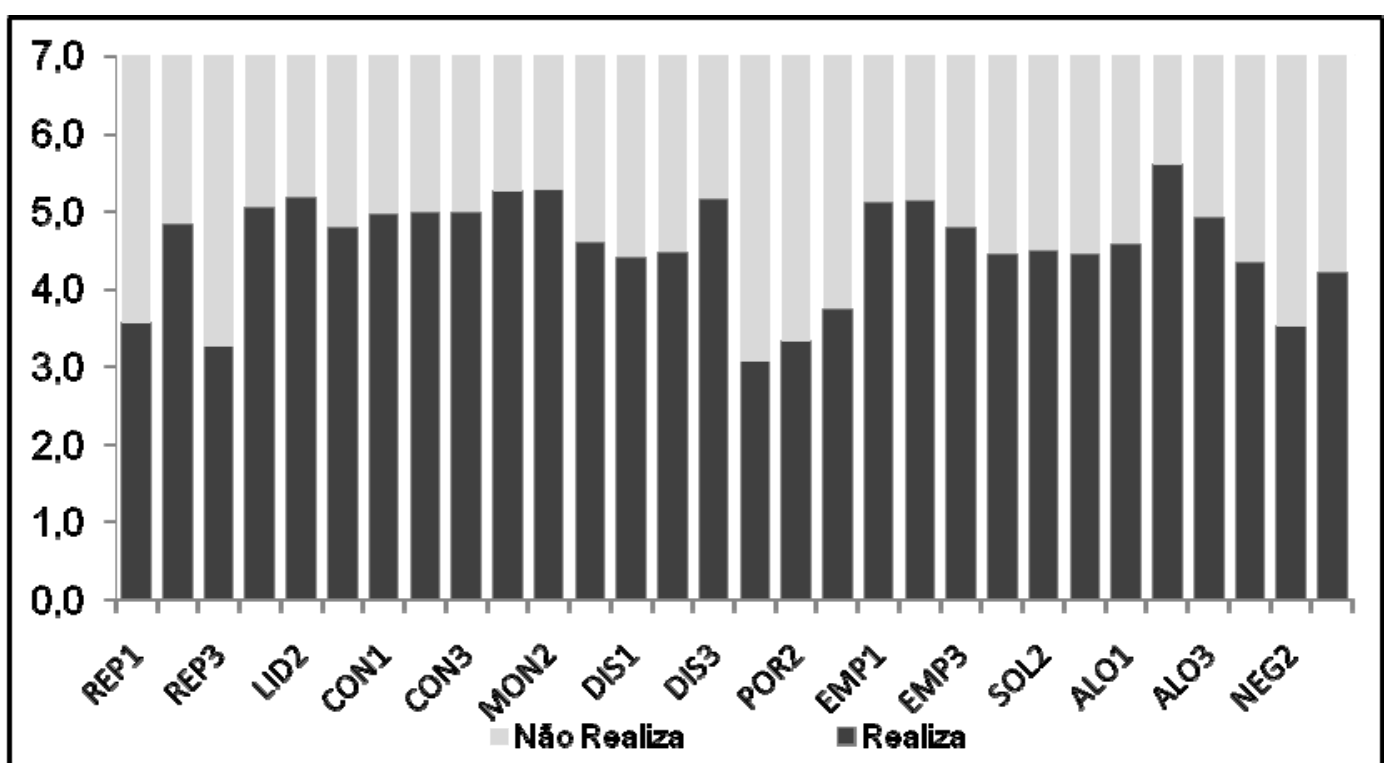

Gráfico 1 - Médias dos valores atribuídos aos papéis

Quanto aos valores dos desvios-padrão, o menor valor foi de 1,5 para um item do papel Monitor e o maior, 2,0, para itens dos papéis de Representante e Alocador, conforme gráfico 2. Sobressaem, nessa primeira análise, como papéis de maior relevância Liderança, Contato, Monitor, Empreendedor e Alocador de recursos, pois possuem médias próximas de cinco.

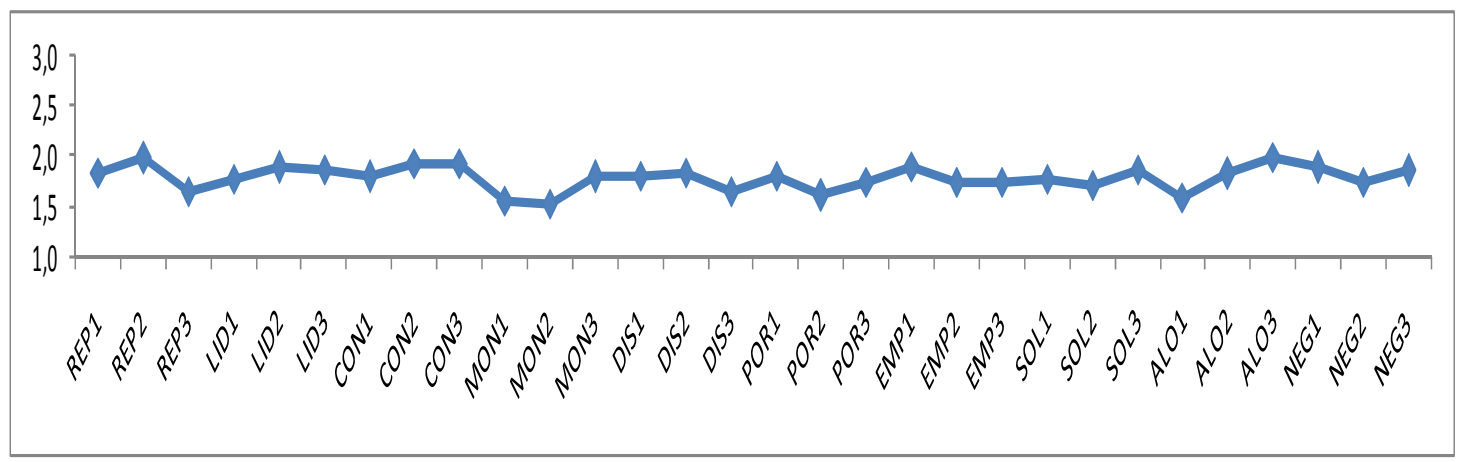

Gráfico 2 - Desvio-padrão dos valores atribuídos aos papéis

Para a aplicação dos testes multivariados, criou-se para cada construto uma nova variável com o valor médio dos três itens do construto. Assim, reduziu-se o conjunto inicial de trinta variáveis para dez variáveis padronizadas.

Para verificar a existência de agrupamentos homogêneos de estilos de trabalho dos empresários, aplicou-se a análise de agrupamento, também conhecida como análise Q, construção de tipologia, análise de classificação e análise numérica. Essa abordagem é útil para desenvolver hipóteses e também para examinar hipóteses previamente estabelecidas (HAIR et al, 2006). Foram utilizadas as abordagens por método hierárquico e não-hierárquico. Primeiramente, foi utilizada a abordagem hierárquica para verificar a estrutura de grupos contida nos dados, o que permitiu eleger um número de grupos para, a seguir, ser processada por abordagem não-hierárquica, a fim de compreender melhor o perfil dos grupos definidos. 


\section{O TRABALHO DO DIRIGENTE DA PEQUENA EMPRESA PODE SER DESCRITO PELOS PAPÉIS DO ADMINISTRADOR?}

Os procedimentos hierárquicos constroem uma estrutura em árvore denominada dendrograma, que representa a formação dos grupos. Essa abordagem identifica e combina dois objetos mais semelhantes e não constante do mesmo agrupamento, repetidas vezes, até que todos os objetos estejam em um único grupo, enquanto que os procedimentos não-hierárquicos classificam objetos nos k grupos pré-fixados (HAIR et al, 2006).

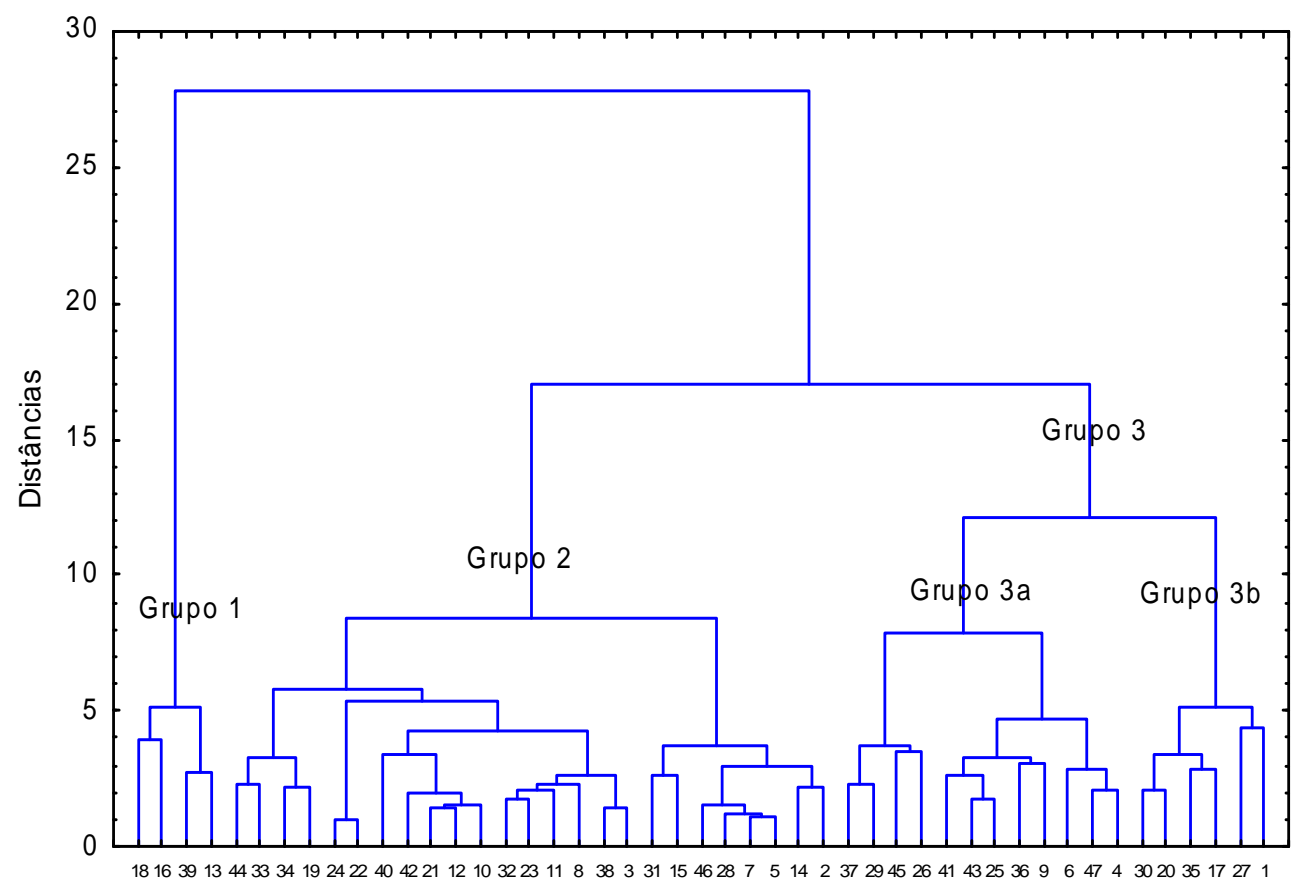

Figura 2 - Dendrograma com a arquitetura de grupos dos dados das empresas

$\mathrm{Na}$ abordagem hierárquica, utilizou-se como medida de semelhança a distância euclidiana e como estratégia de agrupamento o método de Ward. Inicialmente, realizou-se um agrupamento dos papéis. As empresas foram classificadas em três grupos, sendo um deles, o Grupo 3, subdividido em outros dois grupos, 3a e 3b, conforme figura 2, que também mostra um padrão diferenciado do Grupo 1, quando comparado aos Grupos 2 e 3.

A tabela 4 mostra o perfil dos Grupos 1, 2 e 3. No grupo 1, predominam as empresas de comércio com faturamento até 240 mil reais e os dirigentes com graduação. No grupo 2, predominam as empresas de serviços e indústria com faturamento de até 240 mil reais e o nível de escolaridade dos dirigentes como ensino médio. No grupo 3, aparecem também as empresas do setor de comércio, com faturamento até 240 mil reais e o nível de escolaridade dos dirigentes é dividido entre o ensino médio e superior.

Tabela 4 - Perfil dos grupos do agrupamento

\begin{tabular}{lcccc}
\hline & & Grupo 1 & Grupo 2 & Grupo 3 \\
\hline Setor & & & $60 \%$ & $18 \%$ \\
& Serviço & $25 \%$ & $3 \%$ & $64 \%$ \\
Comércio & $75 \%$ & $-18 \%$ \\
Indústria & - & $30 \%$ & $1 \%$ \\
\hline Agroindústria & - & $7 \% \%$ & $75 \%$
\end{tabular}




\begin{tabular}{|c|c|c|c|}
\hline $\begin{array}{r}\text { Acima de } 240 \text { mil até } 2,4 \text { milhões } \\
\text { Acima de } 2,4 \text { milhões }\end{array}$ & - & $\begin{array}{l}34 \% \\
4 \%\end{array}$ & $25 \%$ \\
\hline $\begin{array}{r}\text { Até primeiro grau } \\
\text { Ensino médio } \\
\text { Graduação }\end{array}$ & $\begin{array}{c}25 \% \\
- \\
75 \%\end{array}$ & $\begin{array}{l}15 \% \\
56 \% \\
29 \%\end{array}$ & $\begin{array}{l}7 \% \\
43 \% \\
50 \%\end{array}$ \\
\hline Idade dos respondentes & $\begin{array}{r}42 \\
12.5 \\
\end{array}$ & $\begin{array}{r}39 \\
6 \\
\end{array}$ & $\begin{array}{r}44,7 \\
4,4 \\
\end{array}$ \\
\hline $\begin{array}{rr}\text { Tempo de vida da empresa } & \\
& \text { Média } \\
\text { DP }\end{array}$ & $\begin{array}{l}14 \\
16 \\
\end{array}$ & $\begin{array}{r}11,4 \\
9,8 \\
\end{array}$ & $\begin{array}{l}14,1 \\
11,6\end{array}$ \\
\hline $\begin{array}{r}\text { Número de funcionários - } 2009 \\
\text { Média } \\
\text { DP }\end{array}$ & $\begin{array}{l}1,5 \\
1,9 \\
\end{array}$ & $\begin{array}{l}10 \\
11 \\
\end{array}$ & $\begin{array}{l}20 \\
53 \\
\end{array}$ \\
\hline
\end{tabular}

Fonte: tratamento dos dados.

$\mathrm{Na}$ sequência, após adotar como 3 o número de grupos contido no dendrograma (Figura 2), aplicou-se aos dados o método k-means, que pertence aos métodos de agrupamento não-hierárquico. Os perfis ou centroides de cada grupo são mostrados na Figura 3.

As médias contidas nos centroides da figura 3 mostraram que os empresários do Grupo 2, o grupo central, realizam pouco as funções de Representante e Solucionador de distúrbios. Eles concentram-se mais nas funções de Líder, Contato, Monitor e Disseminador.

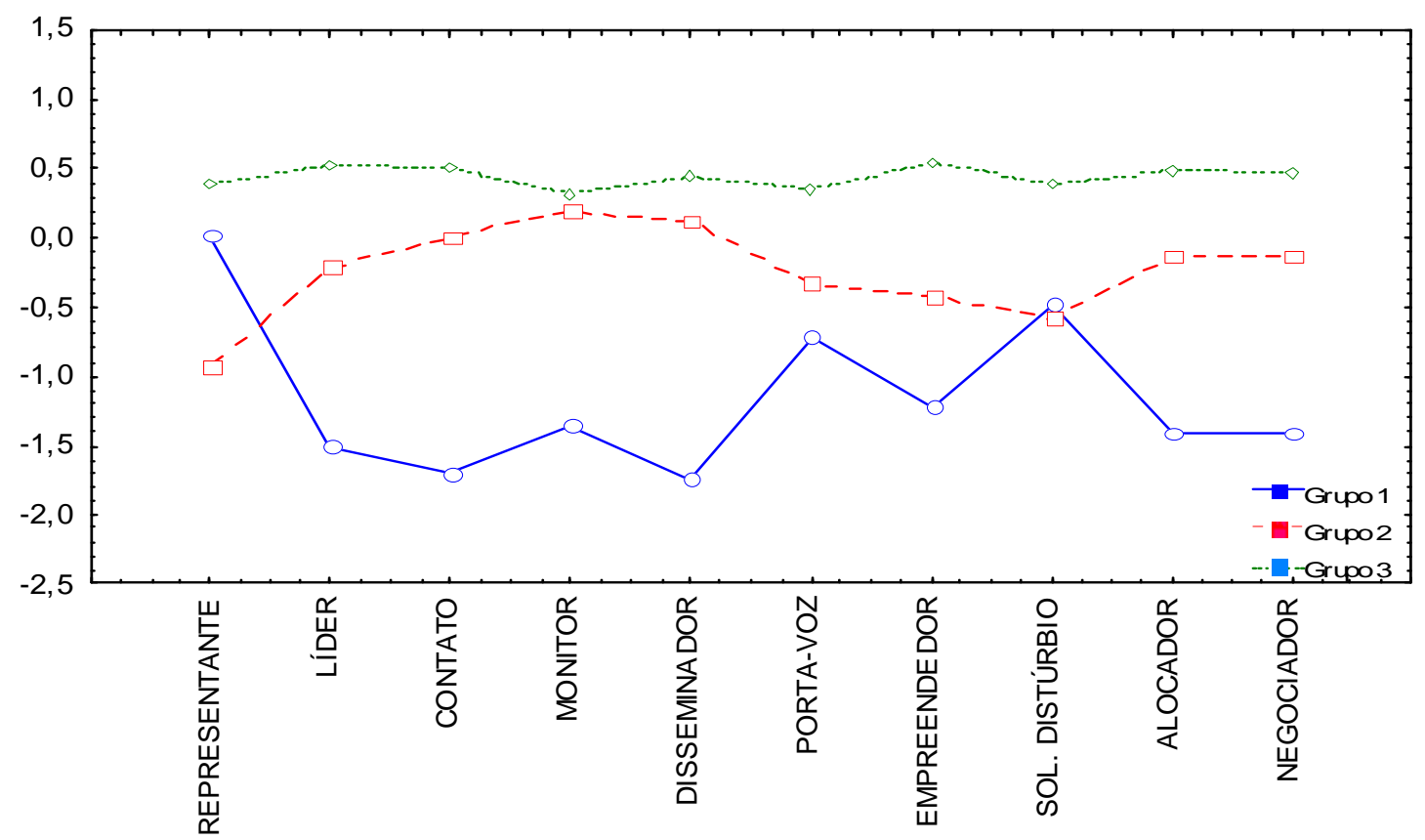

Figura 3 -Centroides dos grupos resultantes da análise de agrupamento por método nãohierárquico k-means

Os resultados do teste $\mathrm{T}^{2}$ de Hotelling sugerem a rejeição da igualdade $(\mathrm{p}<0,05)$ entre os centroides dos três grupos (hipótese $\mathrm{H}_{\mathrm{o}}$ ), admitindo-se haver diferenças entre centroides (hipótese alternativa $\mathrm{H}_{1}$ ), conforme Tabela 5 . 


\section{O TRABALHO DO DIRIGENTE DA PEQUENA EMPRESA PODE SER DESCRITO PELOS PAPÉIS DO ADMINISTRADOR?}

Tabela 5 - Teste T2 de Hotelling entre os 3 Grupos 1, 2 e 3

\begin{tabular}{crrrrc}
\hline Grupos & Value & $\mathbf{F}$ & Effect & Error & $\mathbf{p}$ \\
\hline G1-G2 & 9,064608 & 8,158147 & 10 & 9 & 0,002081 \\
G2-G3 & 3,225536 & 9,031501 & 10 & 28 & 0,000002 \\
G1-G3 & 7,389398 & 12,56198 & 20 & 68 & 0,000000 \\
\hline
\end{tabular}

Na sequência, procurou-se, por meio da análise de componentes principais (ACP), discriminar aquelas empresas com padrões diferenciados quanto à execução dos papéis. Para identificar os componentes principais com maior quantidade relevante de informações, utilizou-se o critério de Kaiser, que considera os autovalores acima de 1 (KAISER, 1958). Os resultados da ACP apontaram que apenas os dois primeiros componentes, CP1 e CP2, possuem autovalores superiores a 1 , retendo ambos $64,3 \%$ da variância contida nas variáveis originais, conforme tabela 6 .

Tabela 6 - Autovalores e Variância obtidos da matriz original de dados

\begin{tabular}{crrr}
\hline Componentes & Autovalores & \% Total da variância & Acumulado \\
\hline 1 & 4,93 & 49,27 & 49,27 \\
2 & 1,51 & 15,11 & 64,38 \\
3 & 0,963386 & 9,63386 & 74,0211 \\
\hline
\end{tabular}

Fonte: tratamento dos dados.

A tabela 7 apresenta as correlações entre os papéis e os dois primeiros componentes principais, enfatizando os papéis com maiores valores. Observa-se uma concentração dos papéis no CP1 com exceção dos papéis de Representante, Porta-voz e Solucionador de distúrbios. $\mathrm{Na}$ apresentação gráfica dos papéis, figura 4, verificou-se quais são as relações entre as descrições dos papéis do administrador e a atuação do dirigente da pequena empresa.

Tabela 7 - Correlação dos Papéis com os componentes principais

\begin{tabular}{lcr}
\hline \multicolumn{1}{c}{ Papéis } & CP 1 & CP 2 \\
\hline REPRESENTANTE & $-0,178149$ & $\mathbf{0 , 5 6 1 3 6 5}$ \\
LÍDER & $\mathbf{- 0 , 3 9 6 6 9 5}$ & $-0,048238$ \\
CONTATO & $\mathbf{- 0 , 3 8 0 0 5 7}$ & $-0,111933$ \\
MONITOR & $-0,295972$ & $\mathbf{- 0 , 4 0 6 8 7 9}$ \\
DISSEMINADOR & $\mathbf{- 0 , 3 8 6 4 0 1}$ & $-0,205897$ \\
PORTA-VOZ & $-0,185697$ & $\mathbf{0 , 5 2 6 3 7 0}$ \\
EMPREENDEDOR & $\mathbf{- 0 , 3 6 0 2 1 1}$ & 0,137623 \\
SOL. DISTÚRBIOS & $-0,186392$ & $\mathbf{0 , 3 6 4 5 8 9}$ \\
ALOCADOR & $\mathbf{- 0 , 3 3 2 9 8 0}$ & $-0,181021$ \\
NEGOCIADOR & $\mathbf{- 0 , 3 4 5 9 6 9}$ & 0,019236 \\
\hline Fonte: tratamento dos dados. & &
\end{tabular}

A figura 4 contém a distribuição bidimensional, projeção dos componentes principais (CP1 e CP2), confirmando a existência de três grupos de papéis. O grupo 1, formado apenas pelo papel de Monitor, distante do grupo 3, formado pelos papéis de Representante, Porta-voz 
e Solucionador de distúrbios. O grupo 2, central, apresenta os papéis de Empreendedor, Negociador, Líder, Contato, Disseminador e Alocador, mais próximo da realidade da pequena empresa.

Figura 4 - Distribuição das empresas nos dois primeiros componentes principais

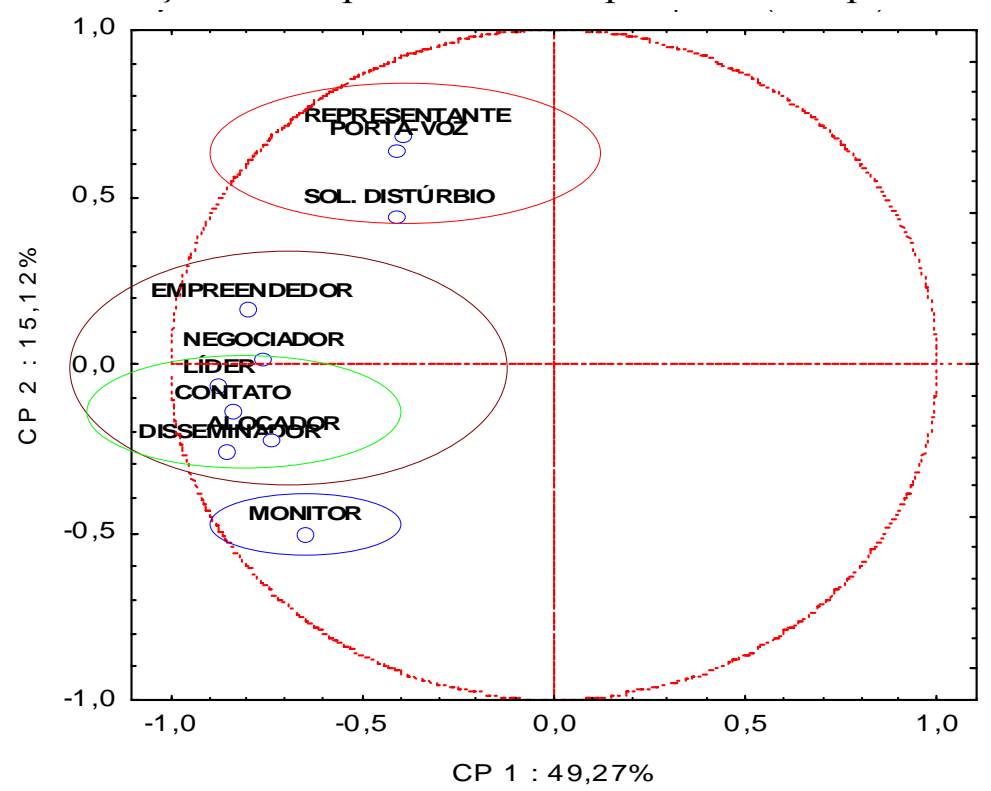

A figura 5 apresenta as posições das empresas relativas aos dois componentes principais. Observa-se que, nas empresas 2 e 44, casos extremos mostrados no segundo agrupamento da análise de cluster encontram-se no grupo destacado. Isso revela que a maioria das pequenas empresas pratica com maior ênfase os papéis do grupo 2.

Figura 5 - Distribuição das empresas nos dois primeiros componentes principais

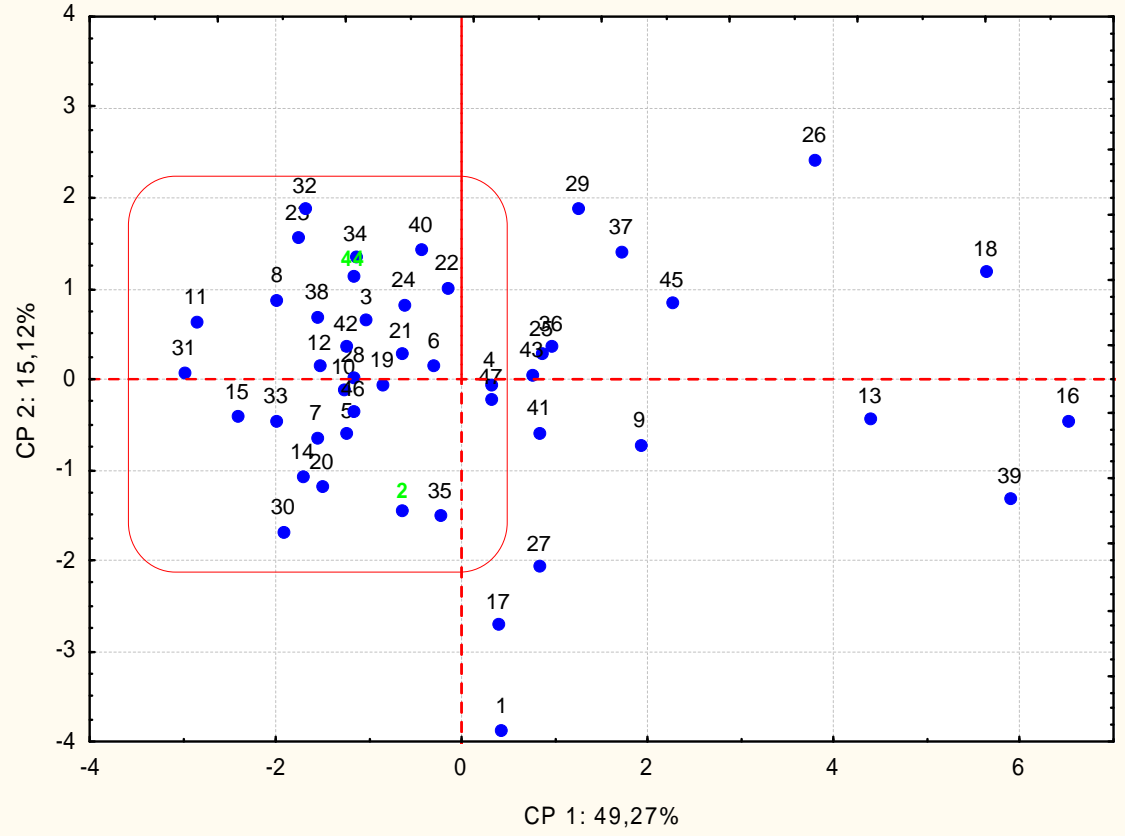




\section{O TRABALHO DO DIRIGENTE DA PEQUENA EMPRESA PODE SER DESCRITO PELOS PAPÉIS DO ADMINISTRADOR?}

Não se busca, neste estudo, validar modelos. Ao se utilizar testes estatísticos, procurou-se, a partir dos resultados, promover discussões sobre proposições do trabalho do dirigente da pequena empresa. Assim, observa-se que, das três categorias de papéis descritas por Mintzberg (1973; 1975), o de dirigente da pequena empresa realiza mais os papéis presentes na categoria Decisional, seguida pela Interpessoal e pela Informacional, conforme fígura 6.

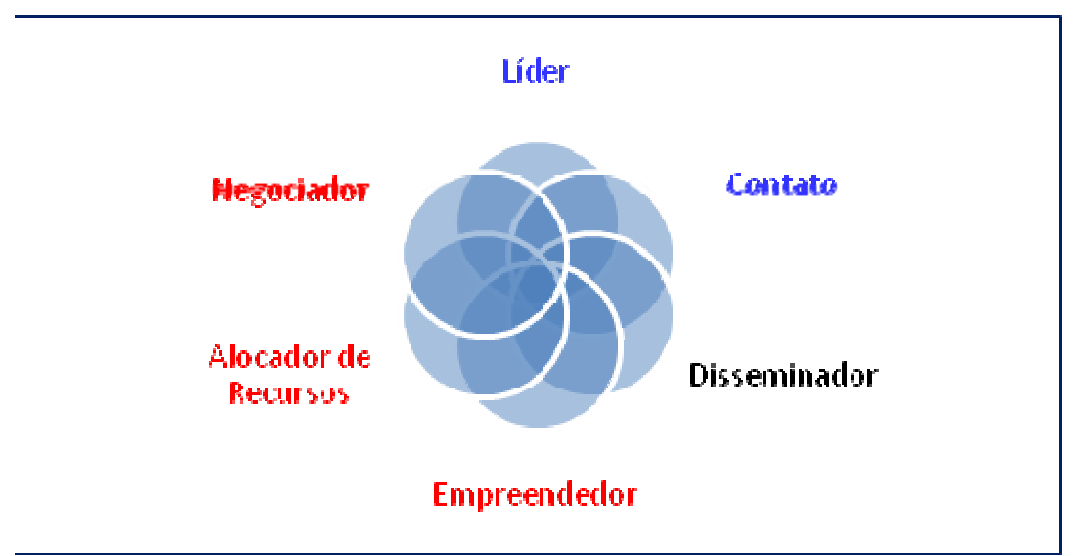

Figura 6 - Papéis mais representativos do trabalho do dirigente da Pequena Empresa

$\mathrm{Na}$ categoria decisional, ele realiza os papéis de Empreendedor, Alocador e Negociador. Na Interpessoal, realiza os papéis de Líder e de Contato, enquanto que, na interpessoal, atua apenas no papel de Disseminador. Essa predominância da categoria decisional mostra que a rotina de trabalho do dirigente não é planejada e é voltada à ação. Ela é variada, fragmentada e inconstante (FORÉN, 2006). Somam-se a isso as atividades relacionadas à orientação para execução das atividades, ao trato e ao compartilhamento de informações com os subordinados e pares, presentes nos papéis de Liderança e de Contato. Além disso, apesar de o dirigente não se preocupar com a institucionalização de meios para coleta e disseminação de informação, ele seleciona do ambiente externo algumas informações relevantes para o ramo de atuação e se preocupa em repassá-la aos subordinados quando necessário à realização das tarefas.

A seguir, são examinadas três proposições extraídas das discussões de Julien (1997), Florén e Tell (2003) e Souza e Mazzali (2008):

- Proposição 1 - heterogeneidade versus homogeneidade no trabalho do administrador.

Segundo Julien (1997) e Souza e Mazzali (2008), apesar de a pequena empresa possuir uma condição especial, possuindo várias características comuns, principalmente quando comparadas com as grandes empresas, observou-se que, quanto ao trabalho do dirigente, ela é heterogênea. Os resultados apresentaram três grupos distintos de papéis; deste modo, os resultados apresentados são descrições para o grupo de empresa número 2, grupo central apresentado na tabela 2.

- Proposição 2 - os dirigentes passam a maior parte do tempo em serviços de escritório.

Segundo Florén e Tell (2003), o dirigente, em sua rotina típica, passa a maior parte do tempo em atividades de escritório. Observou-se que o dirigente passa pouco tempo nos papéis vinculados aos trabalhos de escritório. 
- Proposição 3 - os dirigentes são elos de ligação entre a empresa e a comunidade externa e interna, principalmente por meio de contato verbal.

Florén e Tell (2003) mencionam que os dirigentes despendem grande quantidade de tempo em contatos verbais com subordinados, fornecedores, clientes e terceiros. Observou-se que essa situação realmente ocorre: o dirigente é o articulador e o responsável pelos contatos. Geralmente, é ele quem recebe as pessoas importantes interessadas em contatar a organização. Os contatos são mais evidentes no contexto interno, ao passo que, no contexto externo, nas situações que não incluem contatar clientes e fornecedores, ele age, principalmente, de forma passiva. Nessas situações, a iniciativa pelo contato é quase sempre do interessado externo. Os dirigentes participam de atividades externas, mas, em sua maioria, como convidados e não como promotores das ações. Por isso, a baixa incidência de atenção do dirigente em atividades relacionadas ao papel de representante e de porta-voz.

Considerando esses aspectos, entende-se que, na pequena empresa, as atividades de representação são mínimas e as atividades de porta-voz são associadas às ações de mobilização da comunidade setorial. O papel de representante é exercido internamente, e o grau de atenção para as atividades externas é mínimo. Da mesma forma, o papel de porta-voz é exercido por uma pequena parcela de dirigentes, os quais mantêm direta ou indiretamente algum envolvimento com órgãos de classes, seja pela afinidade de propósito, seja por interesses particulares. Para ilustrar, alguns dirigentes desempenham o papel de porta-voz apenas quando eventualmente comparecem em cerimônias de premiação de destaque setorial.

Finalizando esta seção, entende-se que a abordagem dos papéis é útil para descrever o trabalho do dirigente da pequena empresa. Porém, dada a heterogeneidade das características organizacionais das empresas, os dirigentes dedicam maior atenção a um conjunto distinto de papéis, comumente vinculados ao grupo decisional. Assim sendo, precisa ser examinado em mais profundidade: se apenas o conjunto de papéis identificado nesta amostra de empresas responde à necessidade de transposição teórica entre a abordagem dos papéis e a realidade da pequena empresa ou se os dez papéis, mas com tonicidades diferentes de atenção, é que melhor representam o trabalho do dirigente da pequena empresa.

\section{CONCLUSÕES}

Discutiu-se neste trabalho a possibilidade e as implicações da transposição de conceitos oriundos das descrições da abordagem dos papéis para a realidade do trabalho do dirigente da pequena empresa. Entendeu-se que a abordagem dos papéis é útil para explicar o trabalho do dirigente da pequena empresa, considerando os casos investigados. Além disso, chegou-se a um conjunto de papéis mais representativos do trabalho realizado pelo dirigente, conforme figura 6. Quanto aos demais papéis, eles estão presentes na rotina da empresa, mas recebem menos atenção por parte dos dirigentes.

Além das discussões sobre a incidência da abordagem dos papéis, outra contribuição deste trabalho foi o desenvolvimento do instrumento de coleta de dados, o qual se mostrou adequado para captar as ações do dirigente da pequena empresa, considerando as fundamentações teóricas da abordagem dos papéis. 


\section{O TRABALHO DO DIRIGENTE DA PEQUENA EMPRESA PODE SER DESCRITO PELOS PAPÉIS DO ADMINISTRADOR?}

A generalização dos resultados é limitada, em virtude do tamanho da amostra, condição que não impediu neste momento considerar as proposições discutidas como condizentes com a realidade das empresas pesquisadas.

Por fim, sugere-se a realização de novos e complementares estudos para verificar o grau de incidências dos papéis do administrador considerando as formas de inserção da pequena empresa na estrutura industrial (SOUZA; MAZZALI, 2008) e a transição delas nos estágios do ciclo de vida organizacional (OLIVEIRA; ESCRIVÃO FILHO; 2009).

\section{REFERÊNCIAS}

ANDERSON, P.; MURRAY, J.; OLIVAREZ JR., A. (2002) The managerial roles of public community college chief Academic Officers. Community College Review, v. 30, n. 2, nov., p. $1-26$.

CARLSON, S. (1951). Executive Behaviour: History of management thought. New York: Arno Press.

CHURCHILL, N. C.; LEWIS, V. L. (1983). Growing Concerns - Topics of particular interest to owners and managers of smaller businesses. Harvard Business Review, Watertown, mayjun., p.30-50.

D'AMBOISE, G.; MULDOWNEY, M. (1988) Management Theory for Small Business: attempts and requirements. The Academy of Management Review, New York, v. 13, n. 2, apr.

DANCEY, C. P.; REIDY, J. (2006). Estatística sem matemática para a psicologia: usando o SPSS para Windows. Porto Alegre: ArtMed.

DANDRIDGE, T. C. (1979). Children are not "little grown-ups": small business needs its own organizational theory. Journal of Small Business Management, Florida, v. 17, n. 2, p. 53-57, apr.

FILLION, L. (1999). Diferenças entre sistemas gerenciais de empreendedores e operadores de pequenos negócios. Revista de Administração de Empresas, São Paulo, v.39, n.4, p. 6-20, out/dez.

FINK, A. (2005) How to sample in survey. California: SAGE.

FLORÉN, H. (2006) Managerial work in small firmas: summarising what we know and sketching a research agenda. International Journal of Entrepreneurial Behaviour \& Research, Manchester, v. 12, n. 5, p. 272-288.

GIL, A. C. (1999). Métodos e técnicas de pesquisa social. São Paulo: Atlas.

GLIEM, J. A.; GLIEM, R. R. (2003) Calculating, Interpreting, and Reporting Cronbach's Alpha Reliability Coefficient for Likert-Type Scales. Midwest Research to Practice Conference in Adult, Continuing, and Community Education.

HAIR Jr., J. F. ; ANDERSON, R. E.; TATHAM, R. L.; BLACK, W.C. (2006). Análise multivariada de dados. Porto Alegre: Bookman.

HAIR, J. F. JR.; BABIN, B. MONEY, A. H.; SAMOUEL, P. Fundamentos de métodos de pesquisas em administração. Porto Alegre: Bookman, 2005.

HEILBRONER, R. L.; THUROW, L. Entenda a economia. Rio de Janeiro: Campus, 2001. JULIEN, P. (1997). Théorie économique des PME. In: JULIEN, P. Lês PME bilan et perspectives. Québec: Economica.

KAISER H. F. (1958) The varimax criterion for analytic rotation in factor analysis. Psychometrika, v 23, n. 187, p. 187-200. 
KONRAD, A. M.; KASHLAK, R.; YOSHIOKA, I.; WARYSZAK, R. TOREN, N. (2001). What do manager like to do? Organization Management, v. 26, n. 4, p. 401-433.

LEONE, N. M. C. P. G. (1999). As especificidades das pequenas e médias empresas. Revista de Administração, São Paulo: FEA/USP, v. 34, n. 2, p. 91-94, abr/jun.

LEONE, N.M.C.O.G. (1991). A dimensão física das pequenas e médias empresas (P.M.E'S): À procura de um critério homogeneizador, Revista de Administração de Empresas, v. 31, n. 2, abr/jun, p. 53-59.

MINTZBERG, H. (1973). Strategy-making in three model. California Management Review, v. 16, n. 2, p. 44-53.

MINTZBERG, H. (1975). The manager's job: folklore and fact. Harvard Business Review, Watertown , v. 53, n. 4, p. 49-61, jul./aug.

OLIVEIRA, J.; ESCRIVÃO FILHO, E. (2009) Ciclo de Vida Organizacional: alinhamento dos estágios das pequenas empresas em quatro dimensões. Gestão Industrial, v. 5, n. 1, p. 155-176.

PEARSON, C. A. L.; CHATTERJJEE, S. R. (2003) Managerial work roles in Asia. Journal of Management Development, v. 22, n. 8, p. 694-707.

RAUFFLET, E. (2005). O gerente e suas atividades cotidianas. In: DAVEL, E. MELO, M. C. O. (Org.). Gerência em ação. Singularidades e dilemas do trabalho gerencial. Rio de Janeiro: FGV.

SOLOMON, S. A grande importância da pequena empresa. Rio de Janeiro: Nórdica, 1989. SOUZA, M. C. A. F.; MAZZALI, L. (2008) Conceito e espaço da pequena empresa na estrutura industrial: heterogeneidade e formas de inserção. Gestão da Produção, v. 15, n. 3, set./dez., p. 591-603.

STEWART, R. (1976). Contrast in management: A study of different types of managers jobs, their demands and choices. Maidenhead: McGraw Hill.

TORRÈS, O.; JULIEN, P. A. (2005) Specificity and denaturing of small business. International Small Business Journal, v. 23, n. 4, p. 355-377. 